\title{
The transportation planning process in Slovakia
}

\author{
J. Celko, A. Gavulova \& M. Drliciak \\ Department of Highway Engineering, Civil Engineering Faculty, \\ University of Zilina, Slovakia
}

\begin{abstract}
The quality traffic-planning process is an important tool for achieving sustainable traffic. The modern platform for modelling and simulating traffic relations has also begun to be utilized in Slovakia. The Department of Civil Engineering at the University of Zilina uses German software PTV VISION. The complex multi-modal traffic model for Zilina town was created with PTV VISION modules (Visem, Visum, Vissim). The article presents the process of formation, calibration and practical utilization of a traffic model for city traffic problem solution. The micro simulation of critical zones amends the traffic model.

The classic four-stage disaggregate process was applied for Zilina transport modelling. The town was split into 108 traffic zones. The traffic zones were classified by social and demographic characteristics. Six groups of population were classified within the study area. The matrices of interzonal transport relations were used as output data of the VISEM module and the matrices were used for assignments of the traffic network. Parameters in the infrastructure network and traffic zones were defined in the VISUM module.

The result of many years experience in the field of traffic engineering was inserted in the traffic model. We have used our large database of traffic surveys and the results of transport-sociological analyses. The data were useful for the setting and calibration of the traffic model. We set up new local parameters for a distribution function. The impact of new developing areas and induced traffic relations on the central part of Zilina was also observed. Next, the new transport relations and traffic problems were analysed. This chosen part of the transport network was imported into a microsimulation model in the VISSIM. New alternative transport solutions and the impact on the infrastructure loading were explored in microscopic models.

The quality of traffic load depends on the input data in the microsimulation. The best way is by using the complex macroscopic point of view.

Keywords: transportation planning, traffic model, microsimulation, PTV VISION.
\end{abstract}




\section{Introduction}

The detailed analysis of the traffic situation in a road infrastructure system demonstrates the critical condition of a significant part of urban road transport. The traffic load usually exceeds the infrastructure capacity; the intersections are also frequently critical parts of the transport system. The transportation planning process has to be evaluated complexly in all steps. This requirement makes demanding requests of software tools for traffic modelling and claim to take many factors affecting the process into consideration. The mutual compatibility of software for the calculation of macroscopic, mezoscopic and microscopic traffic relations allows one to solve the traffic problems with many variants and at relative short notice.

Traffic town models are infrequent in Slovakia. The model exists in practical terms for only two towns - Bratislava, the capital of Slovakia and Zilina. The results are based on socio-demographic data from transport-sociological surveys and numerous traffic counts.

\section{Transportation planning process in Slovakia}

Transportation planning is a cooperative process designed to foster involvement of all users of the system, such as the business community, community groups, environmental organizations, travelling public, freight operators, and other transport users throughout a proactive public participation process [1].

The changes in the town have generally very fast and strong impact. The new investments in the industry attract new investors, especially in the automobile

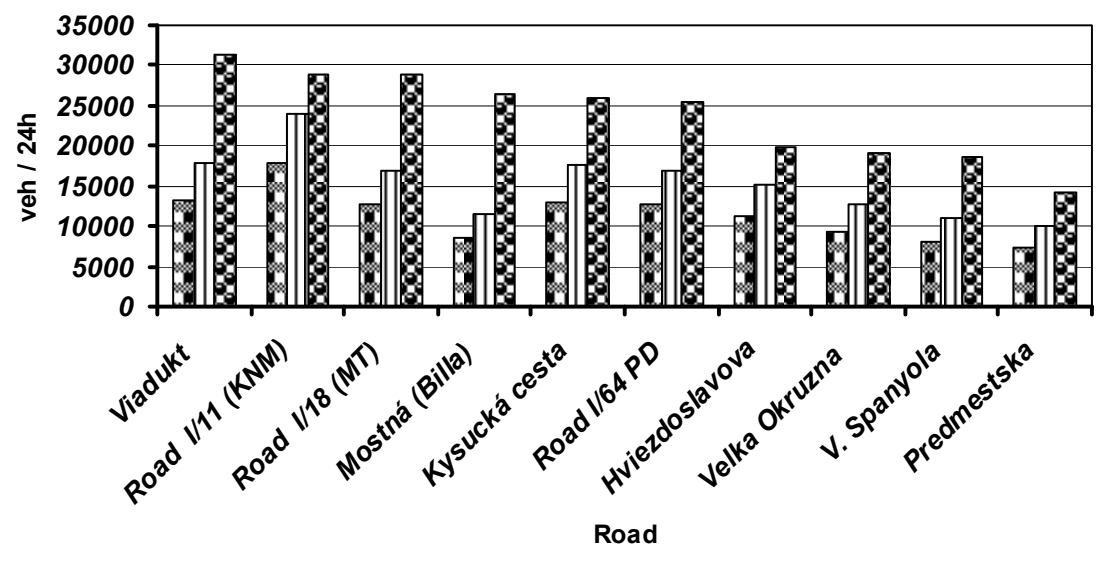

문 19952000 며 2005

Figure 1: $\quad$ AADT (Annual Average Daily Traffic) increase in 1995, 2000 and 2005 [2]. 
industry. Transportation planning documents that are more than 20 years old are not applicable at the present circumstances. The town works on new plans with a modern software support. The knowledge of region history and development is necessary for the transport forecast. Nevertheless, the input data are the biggest problem in a transportation planning process, in Slovakia accordingly. Developing traffic loading is a basic source of the traffic forecast. Figure 1 presents increasing AADT (Annual Average Daily Traffic) in last 15 years. These traffic loads on the main streets in Zilina confirm the terrible present situation [1].

\section{Traffic modelling tools}

The traffic modelling is based on detailed information about the travel demand arising within a study area. In that, the matrices can hardly be generated from travel surveys, mathematical models are used for modelling real traffic demand. The role of the model is to evaluate the number of trips per day between the zones within the study area based on information about inhabitants' behaviour, socioeconomic structure and transport supply. Furthermore, a transport model allows forecast and prediction of scenarios [3].

Generally, two types of models are used. The disaggregate model is used above all at present. Contrary to aggregate model, the disaggregate model evaluates habitants from the point of view of an effect to the transport behaviour in dependence on a trip purpose [3].

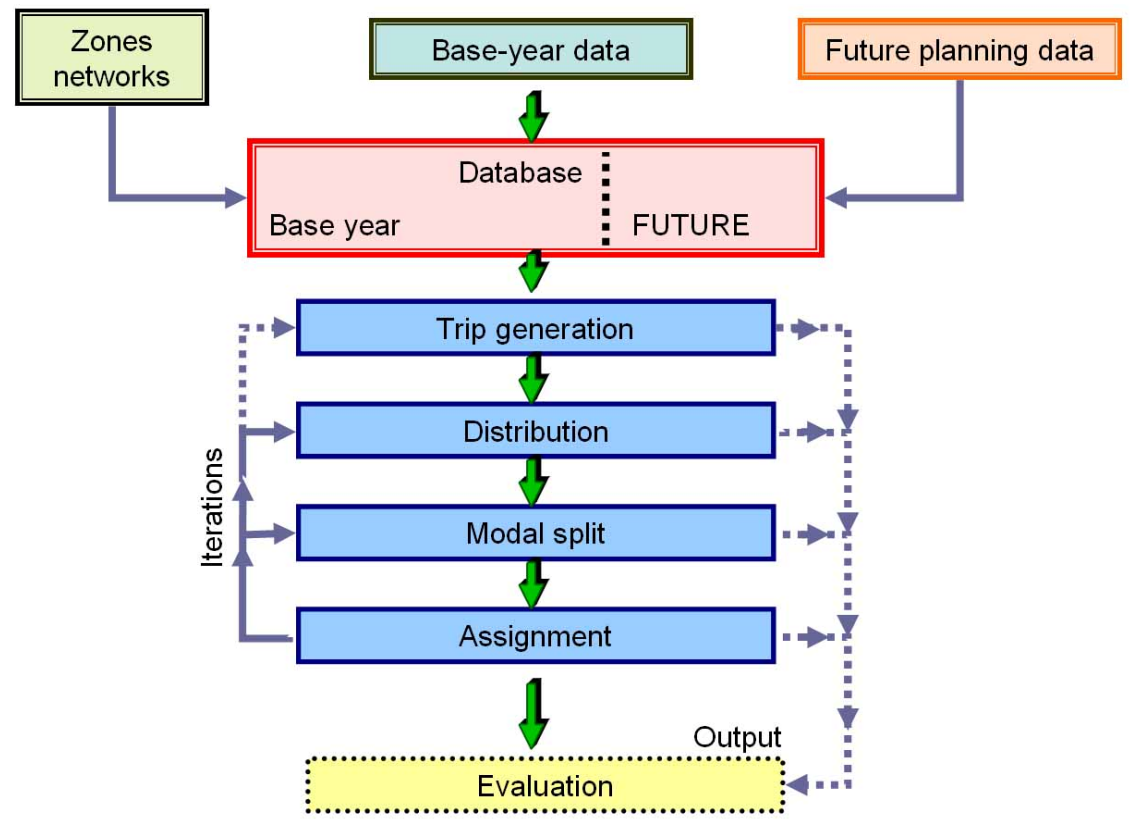

Figure 2: The classic four-stage transport model [4]. 
The solved region is divided into zones dependent on selected parameters which are defined by detailed analysis of urban, transport, economical and sociological conditions. The basic parameter needed for traffic forecast is generation of the trips by origin zones [4].

The number of trips depends on zone character, above all. The greatest source of the trips is a living zone. The majority of the trips are connected with a household. The home based trips mean that one end of the trip is at home (home - work, sport - home, etc). On the other hand, the industrial zones are the most attractive for trips induced by destination zone.

\subsection{Software for transport modelling}

The complex multi-modal traffic model for Zilina town was created with PTV VISION modules. They have used all three software modules. VISEM performs the trip generation (calculation of originating travel demand), trip distribution (specification of destinations) and transport mode choice for travel demand calculations. VISUM integrates all relevant modes of transportation into one consistent network model. It provides a variety of assignment procedures and 4stage modelling components, which include trip-end based as well as activity based approaches. VISSIM is the leading microscopic simulation program for multi-modal traffic flow modelling [5].

\section{Traffic model of Zilina}

Actual traffic situation in the town is deteriorated by creation of new industrial and commercial activities. That is necessarily connected with traffic growth and new transportation relations. Especially the delay of highways D1 and D3 construction in the region has a very important negative effect on the traffic situation in the town [6].

The traffic situation will be improved by finishing the highway network and its connection to the basic urban network, and so the urban network will be unloaded by significant part of transit traffic.

Solutions of traffic problems in the town, which are formatted by the influence of strong inter-zone relations and other development intentions, are necessary to be carried out complexly in general context in order to ensure sustainable regional development. This can be an ensured also by creation of traffic model. The correctly defined traffic model allows evaluating new development activities impact to the road infrastructure loading and allows evaluating alternative solutions of increased traffic problems, too. Accordingly, we can monitor, in addition, the impact of individual phases of highways and highway feeder construction on the urban network loading [1, 7].

\subsection{Traffic model area}

Zilina region (model area) is located in the centre of an important transport and communication junction, where two European multimodal corridors (Va, VI), three international roads (E422, E50, E75 that are included in the network TEM 
and TINA), and three routes of the international railway networks, which will until be soon modernized in compliance with the agreements of AGC and AGTC, meet. Present road transport network in terms of capacity, and constructional and technical quality and accident frequency does not satisfy requirements [7].

\subsection{Traffic model}

The traffic modelling allows a good understanding of real and potential traffic flows and patterns throughout the network, thereby allowing particular solutions to be developed and assessed in terms of their impact in addressing expected demands [3].

The input data of Zilina region issue from transport-sociological analysis. The present specimen is more than 3000 inhabitants, which is about $4 \%$.

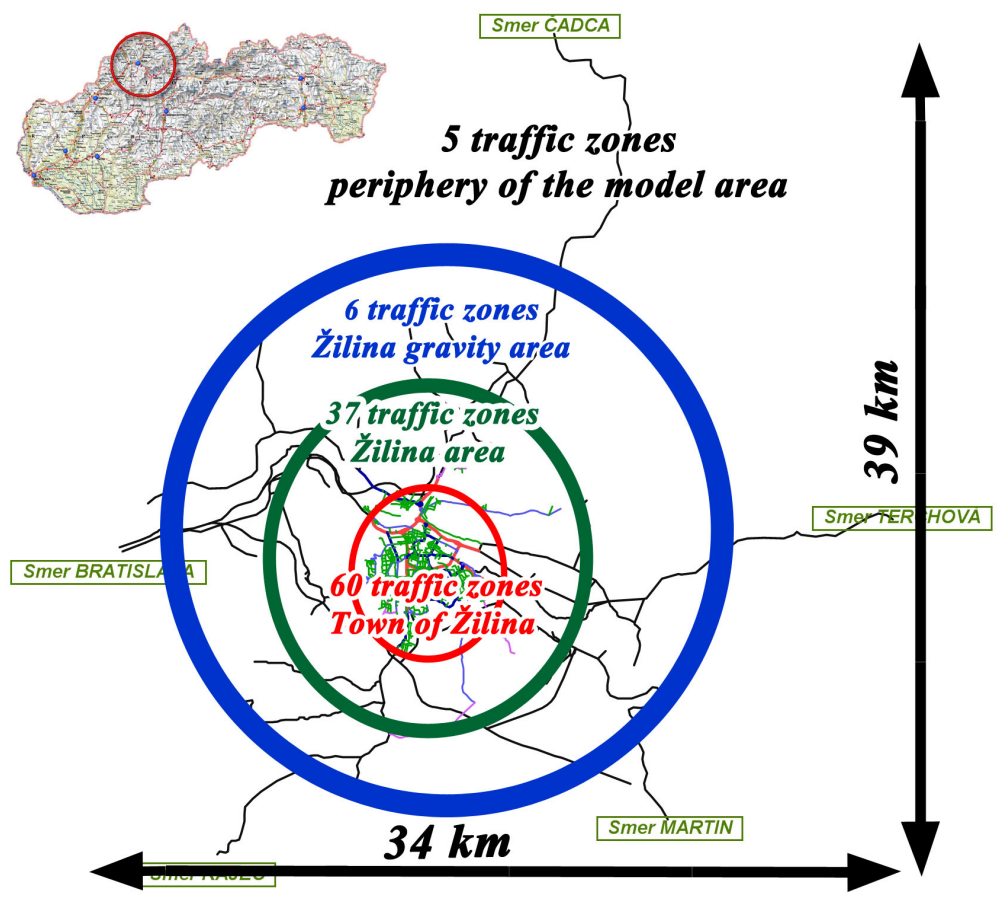

Figure 3: The modelling area.

The traffic model consists of 912 nodes and 2290 links. The division of inhabitants to the specific groups has created homogenous groups characterized by uniform transport behaviour.

The most important parameters of the trip generation are regional economics, regional demographics, and population of the zone and distribution of the subzonal traffic relation. The described parameters are notably affected by car ownership. 


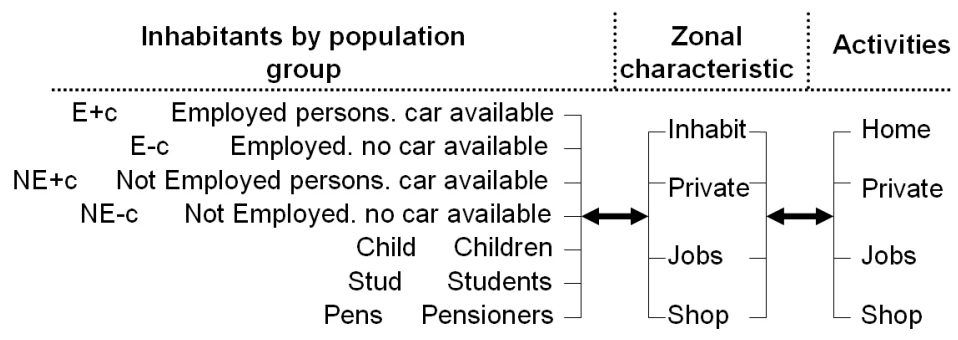

Figure 4: The base division of input data [8].

Philosophy of the zone creation is a very important factor. The traffic model area is divided into 108 traffic zones. The borders of the traffic zones were defined in terms of statistics and urban area structures, and character disposition. The town area is defined into first 60 traffic zones. The area around Zilina is divided other next 37 traffic zones. These zones (villages) represent direct relations with town. The third traffic zone group defines the gravity area. There areas are not connected directly to Zilina town. Last 5 zones are only fictive. The zones define external over regional traffic connection for determination of the origin, destination and transit transport. The fictive zones are located on the periphery of the model area [1].

Number of inhabitants, employment offers, school capacity, commercial service and recreation abilities characterizes each zone. These zones define the demand for travel in terms of origins and destinations within the model trip matrices. The cordoning process described above has resulted in a set of trip matrices for five traffic modes (car, car passenger, bus, cycle and walk) [5].

\subsection{Calibration of traffic model}

The model would be the working tool only in case of its comparability with the real conditions. It has been calibrated by several methods.

The results from transport-sociological analysis have been used for setting parameters. This process has guaranteed traffic behaviour in our region. The default setting was defined for German traffic conditions. The comparison of transport modal split calculated by Visem with results from the survey is displayed in Figure 5. The transport modes are sequenced in the following order: $41 \%$ foot, $28 \%$ public transport, $21 \%$ car-driver, $8 \%$ car - passenger and $2 \%$ bike $[6,9]$.

The comparison of model's results with values from traffic counts is the another way for calibration and check of the network setting. The values are calculated for daylong traffic (continuous traffic). Then the 24-hour trips matrix is commuted to the peak hour matrix. The traffic counts in critical profile position have been made by our department yearly.

Our department cooperates with the Transport enterprise of Zilina. They have given us the public transport trips database. The calculated OD matrix for the public transport is calibrated on the base of their counts. 


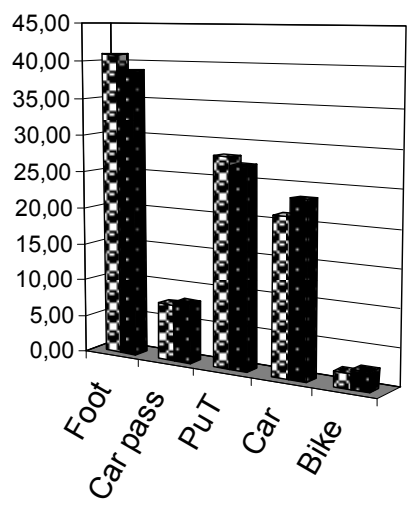

\section{Survey Calculation}

Figure 5: $\quad$ Modal split.

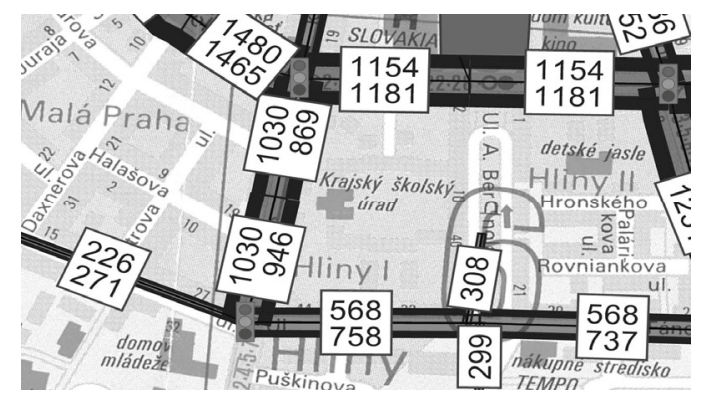

Figure 6: Comparison of real and calculated results.

\section{Practical utilization of Zilina traffic model}

This paper presents a traffic model for Zilina town. The traffic situation was described in the model area, then the model and its calibration for current conditions was set. This part is focused on a practical utilization of the Zilina traffic model.

Most traffic problems in all fast-developing towns are similar. Urban roadtraffic infrastructure is not prepared for increase in traffic load. The traffic network connection of a new shopping centre requires the complex sight on all traffic impacts. New traffic zones with big shopping attraction have been defined. Each zone is characterized by shopping attraction proportion. The new matrices were compared with other results from existing shopping centres. This new demand segment was defined in VISUM network file and the new traffic increase in the main intersection can be observed (Figure 7). The capacity examination of the most loaded crossing has shown unavoidable changes in the traffic control. Traffic counts were made on chosen intersection. The volumes 


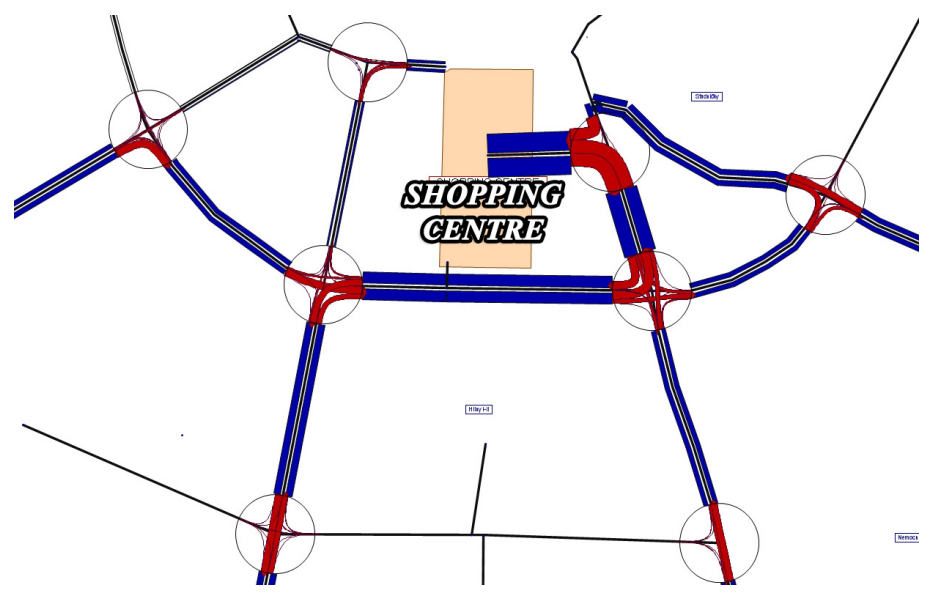

Figure 7: $\quad$ Aggravating traffic load from new shopping centre.

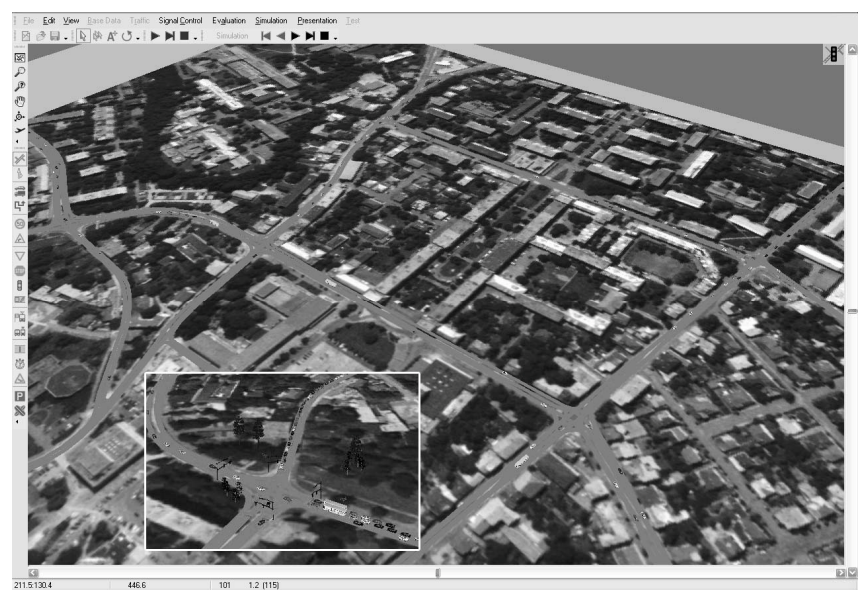

Figure 8: Microscopic simulation.

from peak hour traffic loading were used like input data for a microscopic simulation [5].

The network was assigned with results from traffic counts and with results from demand model calculation. The connecting roads of the new shopping centre were directed by dynamic assignment. Other roads were directed by static roads.

The standard procedure in transportation planning is called Static Assignment. Static means here that the travel demand (how many vehicles want to make trips in the network) as well as the road network itself are constant in time. However, in reality travel demand changes significantly during the day, and even the road network may have time dependent characteristics, e.g. signal 
control may vary during the day. To consider these time dependencies, dynamic assignment procedures are required [2].

The Dynamic Assignment Module is designed to model the route choice behaviour of drivers, thus allowing to model networks without static routes instead using the specification of origin-destination matrices as a flow input. In VISSIM the assignment is done dynamically over time by an iterated application of the microscopic traffic flow simulation [2].

In microscopic model, entries were defined as abstract zone connectors. OD matrix of the shopping centre was exported from Visem calculation with seven rows and seven columns.

Several proposed traffic solutions can be tried at present. The data from network detectors are used for finding the best solution. The new signal plans were calculated according to the newly generated traffic from the shopping centre. The microsimulation model was set for future traffic load for the linked traffic signals.

\section{Conclusion}

The traffic model of Zilina is the first complex model in Slovakia. This way transportation planning process offers to compare and evaluate many versions of traffic problem solutions. That way the traffic model improves the traffic situation in Zilina town. The experience could by applied in other cities.

\section{Acknowledgement}

This paper was prepared with Grant Project VEGA 1/0481/09.

\section{References}

[1] U.S. Department of Transportation, The Transportation Planning Process Key Issues, A Publication of the Transportation Planning Capacity Building Program, FHWA-HEP-07-039

[2] Slovenská správa ciest (Slovak Road Administration), Country traffic count in 1995, 2000 , 2005 (http://www.ssc.sk/sk/Rozvoj-cestnej-siete/Dopravneinzinierstvo/Celostatne-scitanie-dopravy-v-roku-2005.ssc)

[3] Kušnierová, J. - Hollarek, T.: Methodology of modelling and prognosis of the Transport process (in Slovak: Metódy modelovania a prognózovania prepravného a dopravného procesu). Žilina: EDIS, 2000. 166 s. ISBN 807100-673-4

[4] Juan de Dios Ortúzar, Luis G. Willumsen, Modelling Transport, Wiley, pp 23, 2001, ISBN 978-0-471-86110-2 (H/B)

[5] PTV VISION, User's manual Visem and Visum, PTV Planung Transport Verkehr AG, (Software for Transport modelling)

[6] Gavulová, A., Drličiak, M.: Evaluation of road transport infrastructure in the town of Žilina. Regional development and transport logistics: International 
Conference, 6th-7th December, 2006 Žilina, Slovak Republic: proceedings. - Žilina: University of Žilina, 2006. - ISBN 80-8070-622-0. - P. 55-61

[7] Čelko, J. and coll.: Pilot project Žilina, The Regional Development Logistic Park, New Transport Solutions, Project INTERREG III C REDETRAL. Final report. ŽU 11/2006

[8] Čelko, J., Drličiak, M., Gavulová, A.: Transportation planning model, Scientific Letters of The University of Žilina „Communications“, pp. 28 32. 2007 Žilina, ISSN 133-4205

[9] Gavulová, A., Drličiak, M.: The traffic model of Žilina. Mobilita '07: Sustainable mobility in urban areas: 10th International Scientific Conference, May 24-25, 2007, Bratislava, Slovak Republic: Conference proceedings. - Bratislava: STU, Stavebná fakulta, 2007. - ISBN 978-80-2272649-8. - S. 191-196 